\title{
Study on Coupling Effect of Additives on NOx Control in Coal Pyrolysis-Combustion
}

\author{
Xianglu Kong ${ }^{1,3}$, SongYang ${ }^{2,3}$, Shoujun Liu $^{2,3}$, Kaixia Zhang $^{1,3}$, Tingting Jiao ${ }^{1,3}$ and Ju Shangguan ${ }^{1,3^{*}}$ \\ ${ }^{1}$ State Key Laboratory of Clean and Efficient Coal Utilization, Taiyuan University of Technology, Taiyuan 030024, Shanxi, China \\ ${ }^{2}$ College of Chemistry and Chemical Engineering, Taiyuan University of Technology, Taiyuan 030024, Shanxi, China \\ ${ }^{3}$ Shanxi Engineering Center of Civil Clean Fuel, Taiyuan University of Technology, Taiyuan 030024, Shanxi, China
}

\begin{abstract}
A large amount of nitrogen oxides produced by loose coal combustion has an important impact on the ecological environment. To solve this problem, it is proposed to prepare clean coke instead of loose coal combustion to reduce the emission of nitrogen oxides from civil coal combustion. Clean coke is prepared by pyrolysis raw coal adding additives, and the gas generated by pyrolysis is collected uniformly, thus avoiding the emission problem in the process of loose burning. In addition, the clean fuel catalyzes the reduction of nitrogen oxides to produce $\mathrm{N}_{2}$ in the combustion process, thus reducing the emission of combustion nitrogen oxides. In this paper, the additives were investigated, and finally it was found that loading $1 \mathrm{wt} . \% \mathrm{Fe}$ and $\mathrm{Ni}$ had a better effect of decrease nitrogen content in coke through pyrolysis of coal and denitrification during the combustion of coke, and had a coupling effect on nitrogen oxide control in the pyrolysis-combustion process.
\end{abstract}

\section{Introduction}

Coal occupies a large proportion in China's energy consumption, and its status as the main body of energy in China will not change in a short time. But the nitrogen oxides produced by coal combustion will cause environmental problems and other social problems. Therefore, it is very important to study clean fuels for energy reduction. Before coal combustion, a part of volatile nitrogen will be released through a pyrolysis process. If the volatile nitrogen can be effectively controlled, it is helpful to reduce the emission of nitrogen oxides in coal combustion. Sowa et al ${ }^{[1]}$ made relevant research and found that iron additives can really change the law of nitrogen migration, improve the yield of volatile matter, and play an important role in reducing the nitrogen content of coke. He et al ${ }^{[2]}$ carried out swelling treatment on coal, and then carried out pyrolysis with additives $\mathrm{Ca}$, $\mathrm{Co}$ and $\mathrm{Cu}$, found that the better nitrogen removal ratio was $\mathrm{Co}$ and then $\mathrm{Cu}$. In addition, Deng et al ${ }^{[3]}$ found that nitric oxide is always the main component of nitrogen oxides during coal combustion, and its release amount increases sharply with the increase of combustion temperature. Zhu et al ${ }^{[4]}$ found that $\mathrm{Ce}, \mathrm{Co}$ and $\mathrm{Cu}$ additives have better catalytic activity for nitrogen oxides, and iron-cerium composite additives have great synergistic effect on nitrogen oxides control. Lei et al ${ }^{[5]}$ found that the reduction ratio of NO supported by $\mathrm{Mn}-\mathrm{Ce}$ bimetallic promoter was higher than that of single metal. Many scholars have done a lot of work on the control of nitrogen oxides during pyrolysis and combustion. Some additives can really play a good role in reducing the solid nitrogen content during pyrolysis, but the effect during combustion is not good. In the combustion process, it is studied that some additives can reduce NOx in selective catalytic reduction, so as to reduce NOx emission in the combustion process, but they are not suitable for the combustion of loose coal due to limited conditions and other harsh conditions. In view of this, we hope to find a kind of auxiliary agent for combustion of loose coal, which can reduce nitrogen to prepare clean coke during pyrolysis and produce selective catalytic reduction during combustion, so as to play a role in coupling control between coal pyrolysis and combustion, so as to study the coupling control effect of nitrogen oxides and reduce the overall nitrogen oxide emission from coal combustion.

\section{Experimental part}

\subsection{Coal sample treatment}

Firstly, the raw coal is pretreated, crushed and sieved, and the coal sample with a particle size of about $0.2 \mathrm{~mm}$ is dried in an oven at $65^{\circ} \mathrm{C}$ for about 12 hours and taken out for later use, hereinafter abbreviated as CYM. After that, the raw coal was treated by ethanol swelling to expand the molecular network structure of coal and enhance the pyrolysis reaction performance. The swelling treatment method is as follows: $100 \mathrm{~g}$ coal sample with particle size larger than 80 meshes is put in a beaker, mixed evenly according to the ratio of coal to ethanol of 2:1, covered with plastic wrap, stirred in a magnetic stirrer for 6 hours, then stood for 12 hours, and dried in an oven at $50^{\circ} \mathrm{C}$ to

*Corresponding author:shanggj62@163.com 
obtain the swelling coal sample named RZM.

Table 1. Industrial analysis and elemental analysis of raw coal (wt. /\%)

\begin{tabular}{|c|c|c|c|c|c|c|c|c|c|}
\hline \multirow{2}{*}{ Name } & \multicolumn{3}{|c|}{ Industrial analysis } & \multicolumn{6}{|c|}{ Elemental analysis } \\
\hline & $\mathrm{M}_{\mathrm{ad}}$ & $A_{d}$ & $\mathrm{~V}_{\text {daf }}$ & $\mathrm{FC}_{\mathrm{ad}^{*}}$ & $\mathrm{C}_{\mathrm{ad}}$ & $\mathrm{H}_{\mathrm{ad}}$ & $\mathrm{N}_{\mathrm{ad}}$ & $\mathrm{O}_{\mathrm{ad}^{*}}$ & $\mathrm{~S}_{\mathrm{t}, \mathrm{ad}}$ \\
\hline Jet coal & 10.74 & 11.38 & 35.55 & 50.98 & 61.83 & 4.43 & 0.75 & 10.41 & 0.46 \\
\hline Swelling coal & 5.47 & 11.33 & 36.63 & 53.12 & 67.22 & 4.61 & 1.23 & 18.30 & 0.48 \\
\hline
\end{tabular}

Note:d,dry base; ad,air drying base; daf ,dry and ashless; * ,calculated by difference subtraction

\subsection{Additive loading}

In CYM pyrolysis experiment, $\mathrm{FeCl}_{3}, \mathrm{CaCl}_{2}$ and $\mathrm{NaCl}$ additives with $1 \mathrm{wt} . \%$ raw coal were loaded into raw coal by mechanical mixing and stirred evenly. After that, the pyrolysis experiment of RZM adopts the loading mode of equal volume impregnation, and the chloride of metal auxiliary agent is dissolved in proper deionized water, and then coal sample can be added for complete absorption, which is dried in an oven at $65^{\circ} \mathrm{C}$ for $2 \mathrm{~h}$ and taken out for later use.

\subsection{Experimental process}

Pyrolysis experiment: Accurately weigh $4.0000 \mathrm{~g}$ of coal sample and put it into a quartz tube. Under the protection of high purity argon, the temperature is raised from room temperature to $1000^{\circ} \mathrm{C}$ at a rate of $25^{\circ} \mathrm{C} / \mathrm{min}$. After being kept constant for $30 \mathrm{~min}$, it is naturally lowered to room temperature. The solid product coke is collected, the liquid tar is collected from the condenser, and the gaseous products such as $\mathrm{HCN}, \mathrm{NH}_{3}$ and $\mathrm{N}_{2}$ are collected respectively. Wherein nitrogen is collected by an air bag; $\mathrm{NH}_{3}$ and $\mathrm{HCN}$ produced by pyrolysis were absorbed by $1000 \mathrm{~mL}, 0.02 \mathrm{~mol} / \mathrm{L}$ methanesulfonic acid solution and $800 \mathrm{~mL}, 0.1 \mathrm{~mol} / \mathrm{L} \mathrm{NaOH}$ solution respectively. Among them, CYM-1000 refers to coke produced by direct pyrolysis of long flame coal at $1000^{\circ} \mathrm{C}$; CYM-Fe-1000 refers to coke made from long flame coal loaded with 1 wt. $\% \mathrm{Fe}$ at $1000^{\circ} \mathrm{C}$.

Coke combustion experiment is also carried out in a small tube furnace. Every time, weigh $0.5000 \mathrm{~g}$ of coal (coke) sample and put it into a quartz tube,Both sides of the sample are equipped with high-temperature resistant Shi Ying cotton to ensure the uniform passage of gas. First, introduce argon gas to purge the quartz tube to ensure the replacement of air. After the temperature is programmed to the specified temperature and stabilized, switch the gas to $\mathrm{O}_{2} / \mathrm{Ar}$, push the constant temperature zone of the furnace to the charging zone to start the combustion experiment, and use the flue gas analyzer to detect NO in the combustion flue gas online. Coal ash is collected after the experiment is completed for subsequent testing. Each experiment was repeated three times. When the error of parallel experimental data was less than $2 \%$, the average value was taken.

\subsection{Sample analysis and characterization}

Tar nitrogen was determined by chemiluminescence nitrogen analyzer, the concentration of $\mathrm{NH}^{4+}$ and $\mathrm{CN}^{-}$in the absorption solution was determined by solution absorption and detection method. $\mathrm{N}_{2}$ is detected by gas chromatograph. The chromatographic carrier gas is Ar, and the nitrogen content of the collected gas is determined by external standard method. NOx in flue gas is detected online by flue gas analyzer. The components in coke and combustion ash were characterized by XRD.

Calculation formula of coke nitrogen yield and nitrogen removal ratio: coke nitrogen yield $(\%)=$ [nitrogen content in coke $(\mathrm{mg})] /[$ nitrogen content in raw coal $(\mathrm{mg})] \times 100 \%$; Nitrogen removal ratio $(\%)=[1-$ (nitrogen content of coke/nitrogen content of raw coal) $\times 100 \%$ ]. Volatile nitrogen such as $\mathrm{NH}_{3}, \mathrm{HCN}, \mathrm{N}_{2}$ and tar nitrogen are calculated based on the nitrogen content in raw coal. Taking HCN as an example, the formula is: $\mathrm{HCN}$ generation ratio $=[\mathrm{N}$ content in generated $\mathrm{HCN}(\mathrm{mg})] /[\mathrm{N}$ content in raw coal $(\mathrm{mg})] \times 100 \%$. The amount of nitric oxide produced is shown by the following formula:

$$
\mathrm{m}_{\mathrm{NO}}=\mathrm{Q} \times \frac{M_{N O}}{22.4} \times 10^{-6} \int_{0}^{\mathrm{t}} \mathrm{C}_{\mathrm{NO}}(\mathrm{t}) \mathrm{dt}
$$

$\mathrm{m}_{\mathrm{NO}}$-The amount of NO produced by coke combustion,mg

Q-Volume flow of air, $\mathrm{mL} / \mathrm{min}$

$\mathrm{C}_{\mathrm{NO}}(\mathrm{t})$-Volume concentration of $\mathrm{NO}$ in flue gas at time t,ppm

$M_{N O}$-The molar mass of $\mathrm{NO}, 30 \mathrm{~g} / \mathrm{mol}$

\section{Results \& Discussion}

\subsection{Effect of additives on nitrogen distribution in coal pyrolysis}

In order to investigate the influence of the interaction between minerals in raw coal long-flame coal and additives on nitrogen distribution during pyrolysis, pyrolysis experiments were carried out on long-flame coal without and with 1 wt.\% additives in a tube furnace at $1000{ }^{\circ} \mathrm{C}$, and pyrolysis coke, tar and pyrolysis gas were collected and their nitrogen content was calculated, in which $\mathrm{N}_{2}$ is calculated by difference subtraction to achieve nitrogen balance, as shown in Fig. 1.It can be seen from 
the Fig. 2 that iron, calcium and sodium additives loaded in raw coal will reduce the nitrogen content of coke, which shows that the interaction between additives and minerals in coal shows a positive effect on the nitrogen removal from coal, catalyzing the transformation of solid nitrogen in coal to other phases. The nitrogen removal ratio of raw coal and after adding calcium, sodium and iron are $38 \%$, $38.75 \%, 40.07 \%$ and $42.89 \%$ respectively. The best additives for nitrogen removal are iron, then sodium and calcium. It was observed that iron loading caused more coke nitrogen to be converted into $\mathrm{N}_{2}$.

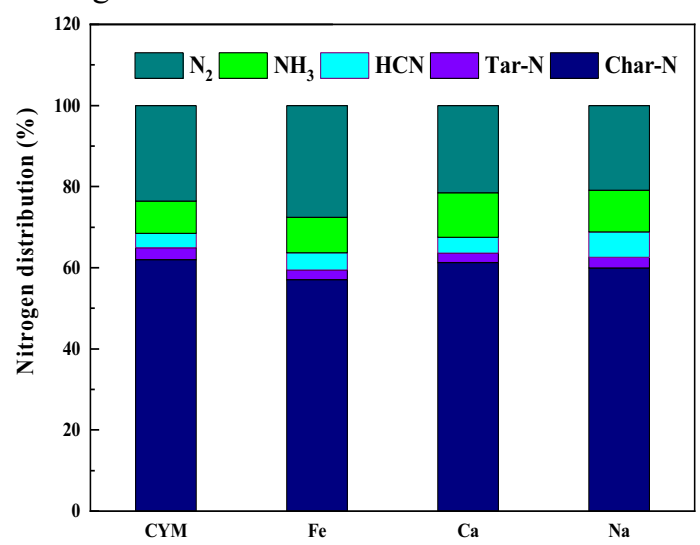

Fig. 1. Nitrogen balance of pyrolysis of raw coal and supported additives at $1000^{\circ} \mathrm{C}$.

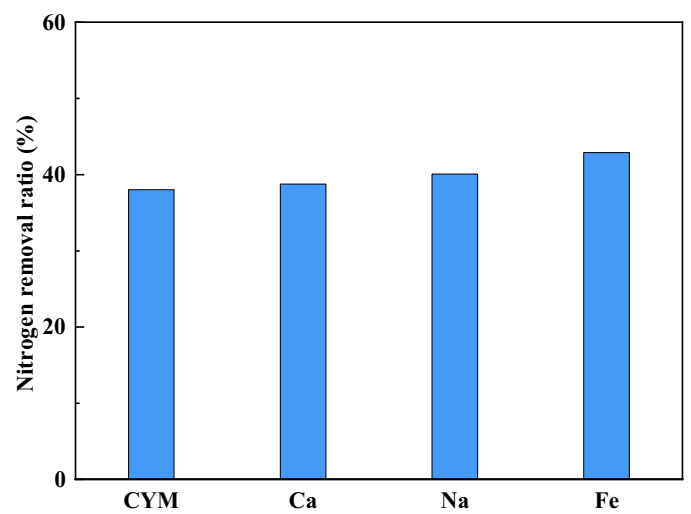

Fig. 2. Nitrogen removal ratio of raw coal pyrolysis with auxiliary agent at $1000^{\circ} \mathrm{C}$.

\subsection{Effect of additives on nitrogen reduction in pyrolysis and denitrification in combustion}

In order to further explore an assistant with better effect in reducing nitrogen in coal pyrolysis and denitration by combustion, experiments were carried out with swelling treated coal as raw coal, and pyrolysis experiments were carried out at $1000{ }^{\circ} \mathrm{C}$ under Ar conditions. Gas-solidliquid three phases were collected to detect their nitrogen content, the overall nitrogen content of tar and $\mathrm{HCN}$ is calculated by difference subtraction to balance nitrogen as shown in Fig. 3. It is observed that when $\mathrm{Ti}, \mathrm{Fe}$ and $\mathrm{Ni}$ are loaded, the nitrogen content of coke is low, and more nitrogen migrates into gas phase $\mathrm{N}_{2}$, and the nitrogen removal ratio are $47.98 \%, 30.72 \%$ and $30.02 \%$, respectively. When loading two metals at the same time for pyrolysis, it is found that the effect of loading iron and cerium is relatively good under this condition, but the overall effect is still not ideal, this shows that the loading of promoter and the loading ratio of composite promoter play an important role in the catalytic activity, and it is necessary to study the catalytic effect of composite promoter separately in the later research. Fig. 4 shows that the coke collected by pyrolysis burns at $1000^{\circ} \mathrm{C}$, and the $\mathrm{NO}$ production is detected and collected online and compared. It is found that the NO production of loaded NiCo-Cu-Fe-Ti compared with swelling raw coal decreases to different degrees, which are $0.2608 \mathrm{mg}, 0.05886 \mathrm{mg}$, $0.0676 \mathrm{mg}, \quad 0.1560 \mathrm{mg}, \quad 0.1927 \mathrm{mg}$ and $0.2467 \mathrm{mg}$ respectively. In the combustion process, it is found that $\mathrm{Ni}$, $\mathrm{Co}$ and $\mathrm{Fe}$ have better effects on inhibiting NO generation.

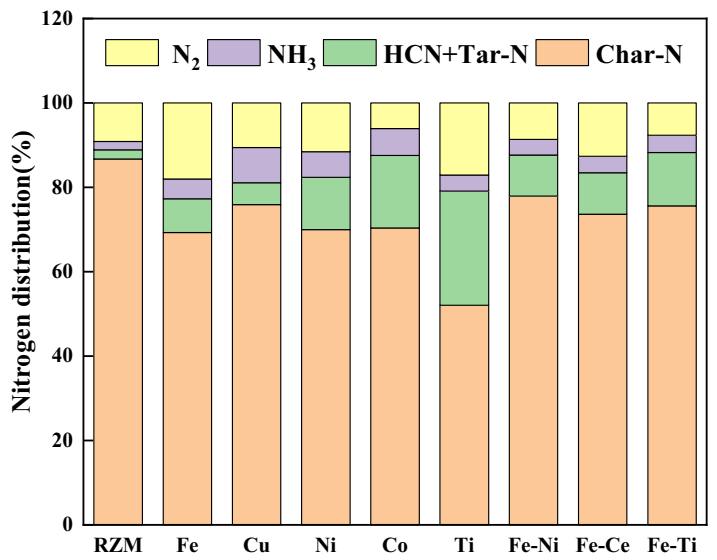

Fig. 3. Nitrogen balance of swelling coal and supported additives during pyrolysis at $1000^{\circ} \mathrm{C}$.

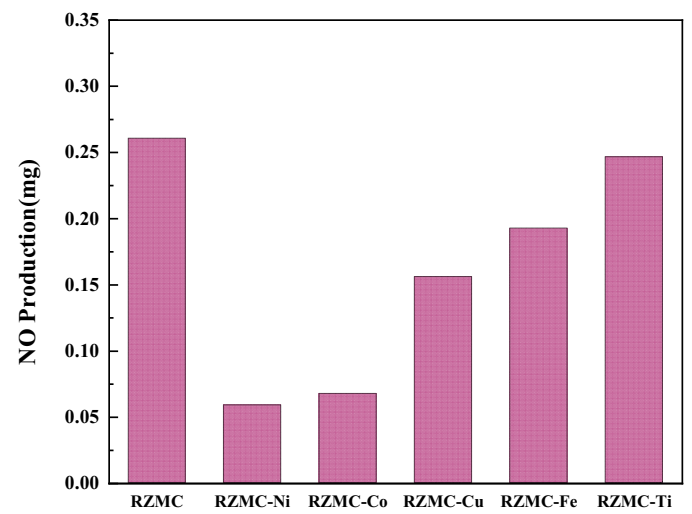

Fig. 4. NO production of swelling coal and supported additives during combustion at $1000^{\circ} \mathrm{C}$.

\subsection{Coupling effect of additives on coal pyrolysis-combustion process}

In order to explore the coupling control effect of additives on nitrogen reduction in pyrolysis and NOx removal in combustion, the coupling control effect of pyrolysis on combustion was explored by adding $\mathrm{Ni}, \mathrm{Fe}$ and $\mathrm{Ti}$ additives with better effect in pyrolysis and combustion. Coke combustion is also carried out at $1000^{\circ} \mathrm{C}$, and other conditions are completely consistent with pyrolysis and combustion conditions except for different ways of adding additives. RZMC-M indicates that the coke prepared by swelling coal loaded with auxiliary agent $\mathrm{M}$ burns at $1000{ }^{\circ} \mathrm{C}$, and $\mathrm{RZMC}+\mathrm{M}$ indicates that swelling coal pyrolysis coke burns at $1000^{\circ} \mathrm{C}$ with auxiliary agent $\mathrm{M}$. It can be clearly seen from Fig. 5 that nickel, iron and 
titanium additives loaded in the combustion of the original coal char can inhibit the release of NO to a certain extent. This shows that the supported additives play a certain role in reducing nitrogen and denitration during pyrolysis or combustion. It can be seen from the above figure that purple represents coke combustion after pyrolysis of raw coal loaded with additives, and it is found that the NO released by combustion of three additives under the same conditions is less than that by adding additives to pyrolysis coke represented by yellow, which shows that the coupling effect of nitrogen oxide control does exist in the pyrolysiscombustion process. This is because the additives added before pyrolysis combine with coal to form solid solution in coal pores, and they contact more closely after pyrolysis gas is discharged, which can inhibit the production of nitrogen oxides. Adding additives to coke is only a mixture of solid and solid phases, which can only catalyze the reduction of nitrogen oxides on the surface layer and promote the reduction of nitrogen oxides by coke and $\mathrm{CO}$ in local anoxic environment.

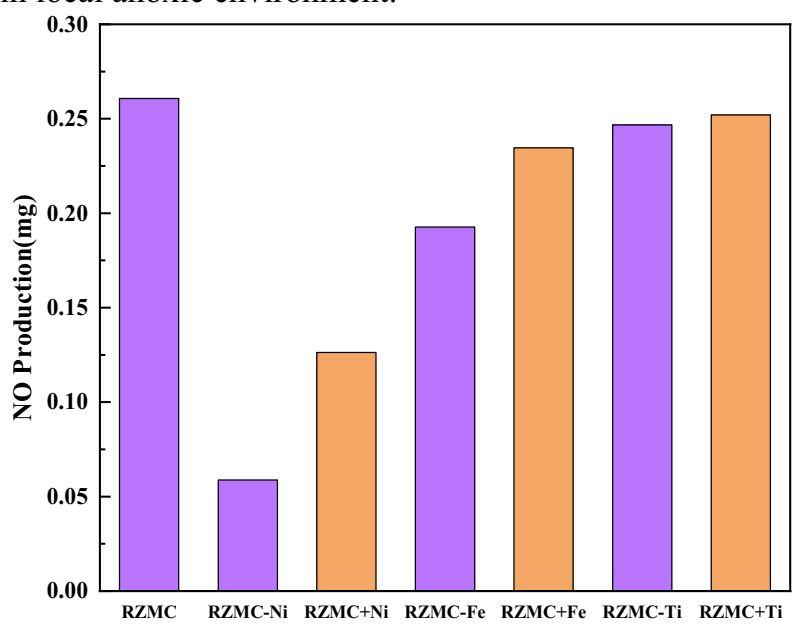

Fig. 5. NO production of swelling coal supported auxiliary coke and swelling coke supported auxiliary combustion at $1000^{\circ} \mathrm{C}$.

\subsection{Phase morphology analysis before and after combustion of coke supported additives}

The coke and combustion ash with good catalytic effect in the above experiment process were characterized by XRD, and their auxiliary forms were detected, as shown in the following Fig. 6 and Fig. 7. XRD characterization analysis was carried out on the prepared coke, and the phase morphology of additives after pyrolysis was determined, the analysis results are shown in Fig. 6. Fe-doped coke has obvious $\mathrm{Fe}_{2} \mathrm{O}_{3}$ and $\alpha$-Fe phases, which indicates that $\mathrm{FeCl}_{3}$ introduced before pyrolysis changes with the increase of pyrolysis temperature, and local oxidation-reduction produces a new iron phase, compared with XRD characterization of ash components after combustion, the results are shown in Fig. 7. According to the analysis of ash, it is found that the iron-containing phase of ash after combustion is only oxide, which may be related to the strong oxidation system of combustion reaction, which indicates that iron oxide in coke participates in the reduction of nitrogen oxides and constitutes the balance of $\mathrm{Fe}, \mathrm{NO}$ and $\mathrm{Fe}_{2} \mathrm{O}_{3}$.

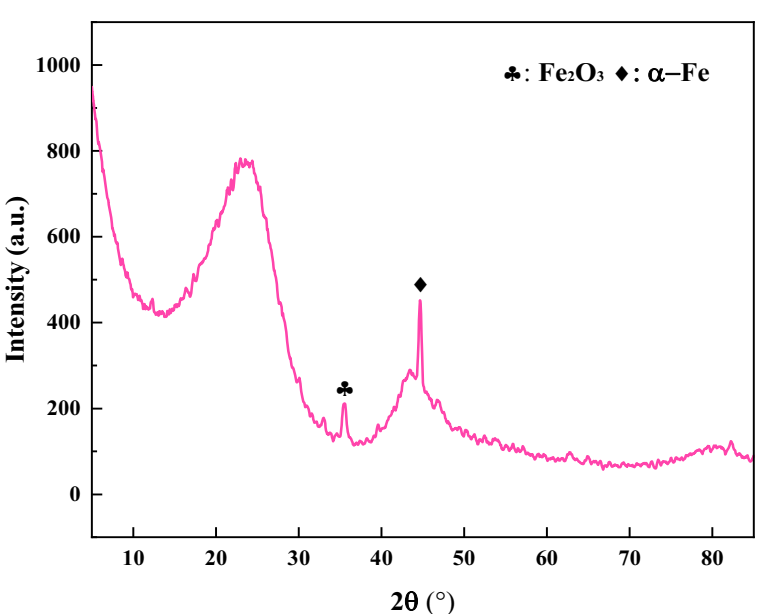

Fig. 6. Iron-containing phase of coke before combustion.

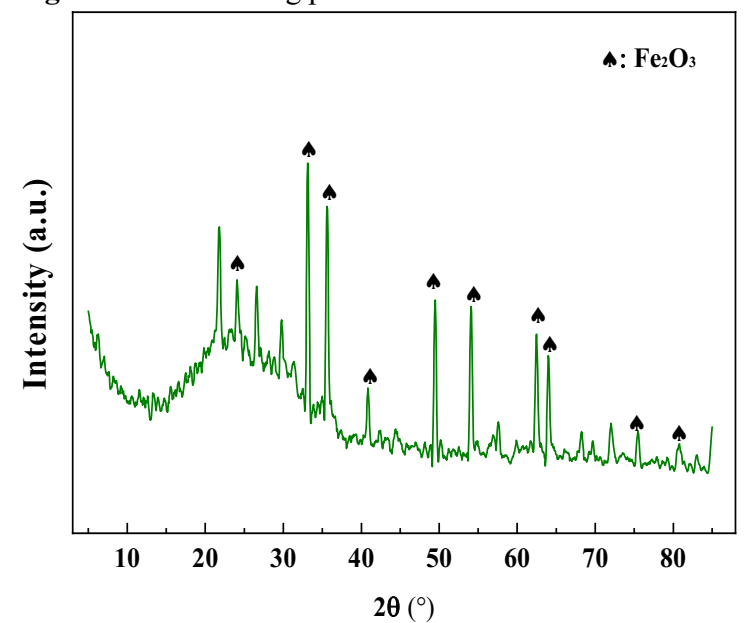

Fig. 7. Iron-containing phase of ash after combustion.

\section{Conclusions}

Coals loaded with $\mathrm{FeCl}_{3}$ or $\mathrm{NiCl}$ can enhance the coupling effect of NOx control during pyrolysis and combustion. When the additive amount is $1 \mathrm{wt} . \%$ and the pyrolysis temperature is $1000{ }^{\circ} \mathrm{C}$, the effect is better, and the denitrification ratio are increased to $30.72 \%$ and $30.01 \%$, respectively. Under these conditions, the combustion of coke loaded with additives has a better effect on reducing NOx emission. On the one hand, the combustion produces less NOx, on the other hand, the catalytic reduction produces $\mathrm{NOx}$ into $\mathrm{N}_{2}$, and the lowest $\mathrm{NO}$ produced when loaded with nickel is $0.05886 \mathrm{mg}$. This shows that the iron and nickel additives introduced in one step have coupling effect on NOx control in coal pyrolysis-combustion process, which promotes the conversion of nitrogen in coal into $\mathrm{N}_{2}$ in pyrolysis process, catalyzes $\mathrm{NOx}$ reduction to $\mathrm{N}_{2}$ in combustion process, and achieves ultra-low NOx emission from clean fuel combustion.

\section{Acknowledgments}

This work was supported by National Natural Science Foundation of China (21878210), Shanxi "1331" Civil Clean Fuel Engineering Research Center, Scientific and Technological Innovation Programs of Higher Education 
Institutions in Shanxi (2019L0313), Patent Promotion and implementation in Shanxi Province (20200719) and sponsored by Taiyuan Green Coke Energy Co., Ltd. (China).

\section{References}

1. S. John, M. Thomas. Fuel Process. Technol, 92, 2211-2218 (2011)

2. C. He, X. Min, H. Zheng. Energy Fuels, 12, 1355813571 (2017)

3. L. Deng, X. Jin, Y. Zhang. Fuel. 175, 217-224 (2016)

4. Z. Lin, Z. Zhong, Y. Han. Korean J. Chem. Eng, 34, 1-9 (2017)

5. Z. Lei, S. Hao, J. Yang. Chemosphere, 270, 128646 (2020) 